\title{
Metabolic syndrome associated with hyperprolactinemia: A new indication for dopamine agonist treatment?
}

\author{
Ignacio Bernabeu • Felipe F. Casanueva
}

Received: 20 February 2013/ Accepted: 25 February 2013/Published online: 22 August 2013

(C) Springer Science+Business Media New York 2013

In this issue of Endocrine, Inancli and co-authors present the manuscript "Effect of cabergoline on insulin sensitivity, inflammation, and carotid intima media thickness in patients with prolactinoma" [1]. They found that cabergoline treatment was associated with significant improvements in body mass index; total, HDL, and LDL-cholesterol levels and insulin sensitivity, also with a decrease in proinflammatory markers and carotid intima media thickness. Only the decrease in total and LDL-cholesterol showed a positive correlation with PRL levels. They concluded that patients with prolactinoma may have a higher vascular risk and cabergoline treatment may be associated with better endothelial function [1].

The human prolactin (PRL) is mainly produced by pituitary lactotrophs under inhibitory control of hypothalamic dopamine. The main and best-known effect of the PRL is the stimulation of lactogenesis and the maintenance of lactation (galactopoiesis). However, PRL is also synthetized in extra-pituitary sites (decidua, myometrium, lymphocytes, and adipocytes) exerting several functions as a "metabolic hormone" [2-4].

The human PRL gene is located on chromosome 6, has six exons and two transcriptional start sites for extra-pituitary and for pituitary PRL. The regulation of $P R L$ gene

\footnotetext{
I. Bernabeu · F. F. Casanueva

Endocrinology Division, Instituto de Investigacion Sanitaria de Santiago de Compostela (IDIS), Complejo Hospitalario Universitario de Santiago (CHUS), Santiago de Compostela, Spain

I. Bernabeu · F. F. Casanueva ( $\square)$

Department of Medicine, CIBER de Fisiopatologia Obesidad Y Nutricion (CB06/03), Instituto Salud Carlos III, Santiago de Compostela University, Santiago de Compostela, Spain

e-mail: endocrine@usc.es
}

transcription is also different, requiring interaction with Pit-1 at pituitary level and with several not well-known tissue-specific factors for each extra-pituitary site [4]. However, the final protein, PRL, is the same at pituitary and extra-pituitary sites. In contrast with the pituitary PRL secretion, the regulation of PRL extra-pituitary secretion is largely unknown.

The PRL receptor is widely expressed in human body and mediates PRL actions by activation of JAK2/STAT5, PI3K, and MAPK pathways [4]. Regardless of its origin, PRL is able to interact with PRL receptors of any body location. However, the mechanisms regulating the expression of PRL receptor (and its different isoforms) in each extra-pituitary tissue are basically unknown. This complex system could explain the absence of relationship between circulating PRL levels and some of the metabolic effects (mainly autocrine or paracrine) of PRL.

The metabolic (extra-mammary gland) effects of PRL have been reviewed elsewhere [2-5] and can be summarized as follows: (a) during the perinatal and postnatal periods pancreatic islet cells development and insulin secretion are promoted; (b) food intake and weight gain are also promoted; (c) adipogenesis inhibiting lipolysis is stimulated, which alters the release of adipokines including leptin, adiponectin, and inter-leukin 6, promoting insulin resistance, hyper insulinemia, endothelial dysfunction, and metabolic syndrome; (d) citrate production in prostatic cells is stimulated and finally, (e) the negative effects of glucocorticoids on the immune system during stress are counteracted [6].

The appropriate treatment with dopamine agonists in patients diagnosed with hyperprolactinemia have been associated with variable reduction in weight [1,7], body fat [8], cardiovascular risk markers, cholesterol [1,9-11], and endothelial dysfunction [1]. In patients with chronic kidney 
disease, PRL level is directly associated with endothelial dysfunction and within increased risk of cardiovascular events and mortality [12]. Furthermore, even with PRL levels in the normal range, a positive association has been found between higher PRL tertiles and all-cause and cardiovascular mortality in both sexes and cancer deaths in men [6].

There are not epidemiological studies on the prevalence of metabolic syndrome in patients with hyperprolactinemia. However, the PRL multiple metabolic effects, leading to metabolic syndrome, are well-documented in animal and human cell lines studies [2-4]. Furthermore, several clinical studies with a few patients-have shown us the metabolic benefit of hyperprolactinemia treatment [1, 7-12].

The metabolic consequences of hyperprolactinemia have long been unknown or overlooked. In current guidelines [13], the metabolic status of patients with hyperprolactinemia is not taken into account for the indication of active treatment. We need larger prospective studies for a better understanding of the metabolic and cardiovascular impact of hyperprolactinemia and its treatment. Probably in the next future we must assess the metabolic status of the patients with hyperprolactinemia to decide about their treatment, forgetting PRL as a hormone only associated with lactation and with the pituitary gonadal axis.

\section{Referenses}

1. S.S. Inancli, A. Usluogullari, Y. Ustu, S. Caner, A.A. Tam, R. Ersoy, B. Cakir, Effect of cabergoline on insulin sensitivity, inflammation, and carotid intima media thickness in patients with prolactinoma. Endocrine (2012). doi:10.1007/s12020-012-9857-y

2. N. Ben-Jonathan, E.R. Hugo, T.D. Brandebourg, C.R. LaPensee, Focus on prolactin as a metabolic hormone. Trends Endocrinol. Metab. 17, 110-116 (2006)

3. N. Ben-Jonathan, C.R. LaPensee, E.W. LaPensee, What can we learn from rodents about prolactin in humans? Endocr. Rev. 29, $1-41(2008)$
4. T. Brandebourg, E. Hugo, N. Ben-Jonathan, Adipocyte prolactin: regulation of release and putative functions. Diabetes Obes. Metab. 9, 464-476 (2007)

5. K. Dorshkind, N.D. Horseman, The roles of prolactin, growth hormone, insulin-like growth factor-I, and thyroid hormones in lymphocyte development and function: insights from genetic models of hormone and hormone receptor deficiency. Endocr. Rev. 21, 292-312 (2000)

6. R. Haring, N. Friedrich, H. Volzke, R.S. Vasan, S.B. Felix, M. Dorr, Z.U. Meyer, H.E. Schwabedissen, M. Nauck, H. Wallaschofski, Positive association of serum prolactin concentrations with all-cause and cardiovascular mortality. Eur. Heart J. (2012). doi:10.1093/eurheartj/ehs233

7. J. Korner, J. Lo, P.U. Freda, S.L. Wardlaw, Treatment with cabergoline is associated with weight loss in patients with hyperprolactinemia. Obes. Res. 11, 311-312 (2003)

8. E.C. Naliato, A.H. Violante, D. Caldas, A. Lamounier Filho, C.R. Loureiro, R. Fontes, Y. Schrank, R.G. Souza, P.L. Costa, A. Colao, Body fat in nonobese women with prolactinoma treated with dopamine agonists. Clin Endocrinol (Oxf). 67, 845-852 (2007)

9. O. Serri, L. Li, J.C. Mamputu, M.C. Beauchamp, F. Maingrette, G. Renier, The influences of hyperprolactinemia and obesity on cardiovascular risk markers: effects of cabergoline therapy. Clin Endocrinol (Oxf). 64, 366-370 (2006)

10. K. Berinder, T. Nystrom, C. Hoybye, K. Hall, A.L. Hulting, Insulin sensitivity and lipid profile in prolactinoma patients before and after normalization of prolactin by dopamine agonist therapy. Pituitary 14, 199-207 (2011)

11. C.M. dos Santos Silva, F.R. Barbosa, G.A. Lima, L. Warszawski, R. Fontes, R.C. Domingues, M.R. Gadelha, BMI and metabolic profile in patients with prolactinoma before and after treatment with dopamine agonists. Obes. (Silver Spring) 19, 800-805 (2011)

12. J.J. Carrero, J. Kyriazis, A. Sonmez, I. Tzanakis, A.R. Qureshi, P. Stenvinkel, M. Saglam, K. Stylianou, H. Yaman, A. Taslipinar, A. Vural, M. Gok, M. Yenicesu, E. Daphnis, M.I. Yilmaz, Prolactin levels, endothelial dysfunction, and the risk of cardiovascular events and mortality in patients with CKD. CJASN 7, 207-215 (2012)

13. F.F. Casanueva, M.E. Molitch, J.A. Schlechte, R. Abs, V. Bonert, M.D. Bronstein, T. Brue, P. Cappabianca, A. Colao, R. Fahlbusch, H. Fideleff, M. Hadani, P. Kelly, D. Kleinberg, E. Laws, J. Marek, M. Scanlon, L.G. Sobrinho, J.A. Wass, A. Giustina, Guidelines of the pituitary society for the diagnosis and management of prolactinomas. Clin. Endocrinol. (Oxf). 65, 265-273 (2006) 